\title{
Isorhamnetin inhibits amplification of influenza A H1N1 virus inflammation mediated by interferon via the RIG-I/JNK pathway
}

\author{
Jing $\mathrm{Li}^{1,2 \#}$, Yifan $\mathrm{Xu}^{1,2 \#}$, Zhiwei Lin ${ }^{1 \#}$, Lili Guan ${ }^{1}$, Shuqi Chen ${ }^{2,3}$, Luqian Zhou ${ }^{1}$ \\ ${ }^{1}$ State Key Laboratory of Respiratory Disease, National Clinical Research Center for Respiratory Disease, Guangzhou Institute of Respiratory \\ Health, First Affiliated Hospital of Guangzhou Medical University, Guangzhou, China; ${ }^{2}$ Institute of Combination Chinese and Western Medicine, \\ Guangzhou Medical University, Guangzhou, China; ${ }^{3}$ Guangzhou University of Chinese Medicine, Artemisinin Research Center, Guangzhou, China \\ Contributions: (I) Conception and design: J Li, L Zhou; (II) Administrative support: None; (III) Provision of study materials or patients: J Li, Y Xu; (IV) \\ Collection and assembly of data: J Li, Y Xu, Z Lin, S Chen; (V) Data analysis and interpretation: J Li, Y Xu, Z Lin, S Chen; (VI) Manuscript writing: \\ All authors; (VII) Final approval of manuscript: All authors. \\ \#These authors contributed equally to this work. \\ Correspondence to: Luqian Zhou. State Key Laboratory of Respiratory Disease, National Clinical Research Center for Respiratory Disease, Guangzhou \\ Institute of Respiratory Health, First Affiliated Hospital of Guangzhou Medical University, 151 Yanjiangxi Road, Guangzhou 510120, China. \\ Email: zhlx09@163.com.
}

\begin{abstract}
Background: Interferon (IFN) amplifies the influenza virus-mediated inflammatory response by forming a paracrine signal feedback loop, which is considered an important cause of excessive inflammatory damage. Isorhamnetin has a wide spectrum of beneficial pharmacological properties, including anti-inflammatory and antiviral effects. The regulatory effect and mechanism of isorhamnetin on influenza virus-mediated inflammation have not yet been reported.

Methods: We pre-treated A549 cells with IFN- $\beta(50 \mathrm{ng} / \mathrm{mL})$ for $4 \mathrm{~h}$ followed by IAV (H1N1) infection to simulate the inflammation amplification effect caused by the paracrine effect of IFN- $\beta$. The antiinflammation activity of isorhamnetin against amplification inflammation of interferon mediated by IAV (H1N1) was assessed by performing quantitative real-time polymerase chain reaction (qRT-PCR), western blotting, and enzyme-linked immunosorbent assay (ELISA) in A549 cells.

Results: Compared with the virus infection group, the IFN- $\beta$ pretreatment virus infection group had an upregulated level of pro-inflammatory cytokine expression, which was inhibited by isorhamnetin significantly via the retinoic acid-induced gene I (RIG-I)/c-Jun N-terminal kinase (JNK) signaling pathway. Molecular docking studies further verified that isorhamnetin can interact with JNK.

Conclusions: Our work was the first to demonstrate the anti-inflammatory activity and mechanism of isorhamnetin during influenza virus infection. Isorhamnetin significantly improves the excessive inflammatory response mediated by IAV (H1N1) infection mainly via the RIG-I/JNK pathway. Additionally, isorhamnetin exhibited an apparent antiviral effect of $\mathrm{H} 1 \mathrm{~N} 1$ in vitro.
\end{abstract}

Keywords: Isorhamnetin; influenza A virus (IAV); inflammation; type I interferon

Submitted Jun 18, 2021. Accepted for publication Aug 11, 2021.

doi: $10.21037 / \mathrm{atm}-21-3532$

View this article at: https://dx.doi.org/10.21037/atm-21-3532

\section{Introduction}

Influenza is an acute viral respiratory disease that causes significant mortality and morbidity worldwide. Among the influenza viruses that infect humans, influenza A virus (IAV) is the main cause of infection and death (1). The IAV is prone to small changes in protein structure ("antigenic drift"), which makes this virus prone to mutation, thus resulting in new subtypes that cause influenza epidemics. Occasionally, these new subtypes can cause pandemics and pose a wider threat to human life and health (2). At present, 


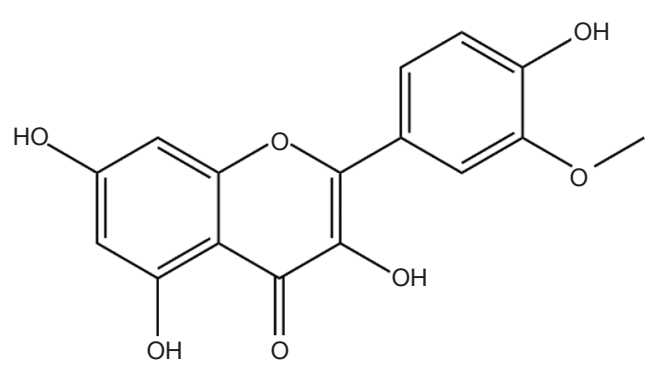

Figure 1 Chemical structure of isorhamnetin.

the 2 most common IAV subtypes in humans are H3N2 and H1N1 (3).

Recently, it has been considered that influenza viruses can not only directly affect the host but also cause indirect effects via severe immunological disorders. Influenza virus infection can promote the secretion of chemokines and cytokines, which contribute to the clearance of viruses from the host. Whereas, in some cases, excessive release of inflammatory cytokines occurs after influenza infection, leading to the so-called "cytokine storm" that can result in multiple organ failure and even death $(4,5)$. The amplification of IFN-mediated inflammation caused by influenza virus is considered to be the main cause of death from severe influenza (6).

After infection, influenza virus is first recognized by pattern recognition receptors (PRRs), most notably the intracellular PRR retinoic acid-induced gene I (RIG-I). The 5'-triphosphate ends of viral single-stranded (ss)RNA are recognized by RIG-I, which results in the activation and translocation of RIG-I to the mitochondria, where it activates the mitochondrial antiviral signaling (MAVS) protein for downstream signaling. This induces the production of type I IFN, cytokines, and chemokines (7). It is well known that IFN is the main molecule involved in the antiviral response (8-10). However, because type I IFNs are pleiotropic cytokines, their effects on the immune response also have the potential for pathogenesis (11). The relationship between influenza virus and type I IFN is complex. For example, despite leading to a lower viral load, the administration of high doses of IFN- $\alpha$ treatment of an Mx-negative influenza-resistant mouse strain resulted in increased morbidity and mortality from influenza rather than protection (12). Similarly, in ferrets challenged with IAV, the survival rate was not increased by IFN- $\alpha$ treatment, despite there being a lower viral load in nasal washings from these animals (13). This phenomenon may be a result of the inflammatory cascade mediated by type I IFN. The possible mechanism behind this pro-inflammatory effect is that RIG-I activates the type I IFN positive feedback loop (6). During infection, IAV can hyperinduce proinflammatory cytokines and chemokines to induce lung inflammation and injury. In particular, the proinflammatory cascade induced by the highly pathogenic influenza virus is more severe than those induced by direct influenza virus infection (14). Thus, when treating patients with influenza, it is critical to regulate the excessive inflammatory response induced by the influenza virus.

Presently, most available anti-influenza drugs target viral molecules, and only 2 anti-influenza drug types can be used clinically: neuraminidase (NA) inhibitors, such as oseltamivir, zanamivir, and peramivir (15); and M2 inhibitors, such as amantadine and rimantadine (16). Unfortunately, the application of these drugs is restricted by their toxicity and the emergence of viral resistance (17). In addition, the frequent alterations in antigenic structures of influenza viruses pose difficulties for production of effective vaccines (18). Targeting the inflammation induced by IAV infection, that is, targeting the host response to the virus rather than targeting the IAV surface glycoprotein, could be a potential alternate anti-influenza therapy.

Natural products derived from bacteria, fungi, and plants have become an important source for drug development because of their diverse and complex chemical components. Recently, natural products have received widespread attention in the field of influenza treatment owing to their low toxicity, multiple targets, and curative effects (19). Isorhamnetin, the chemical structure of which is shown in Figure 1, is a flavonoid that can be isolated from the fruits of sea buckthorn and ginkgo leaves. This compound has numerous pharmacological effects, and its antiinflammatory effects have been extensively studied in conditions such as osteoarthritis, periodontitis, and acute lung injury (ALI) (20-22). In addition, isorhamnetin also has antiviral activity (23). Previous studies in vivo and in vitro have reported that isorhamnetin has a promising antiviral effect against IAV (H1N1) (24); however, there are no reports on whether isorhamnetin can regulate the IAV (H1N1)-mediated immune response. We hypothesized that isorhamnetin modulates the host immune response to influenza virus infection and conducted this study to investigate the regulatory effect of isorhamnetin on IAV (H1N1)-mediated inflammation, with the goal of providing a new approach to the development of anti-influenza therapeutics. We present the following article in accordance 
Table 1 Antibody information

\begin{tabular}{lcccc}
\hline Antibody & Source/isotype & Manufacturer & Art. no. & Molecular weight (kDa) \\
\hline COX-2 & Rabbit & CST & $\# 12282$ & 74 \\
phospho-JNK & Rabbit & CST & $\# 4668$ & $46 / 54$ \\
JNK & Rabbit & CST & $\# 9252$ & $46 / 54$ \\
phospho-p38 & Rabbit & CST & $\# 4511$ & 38 \\
p38 & Rabbit & CST & $\# 9212$ & 38 \\
RIG-I & Rabbit & CST & $\# 3743$ & 102 \\
$\beta$-actin & Rabbit & CST & $\# 2118$ & 37 \\
\hline
\end{tabular}

with the MDAR reporting checklist (available at https:// dx.doi.org/10.21037/atm-21-3532).

\section{Methods}

\section{Cells and viruses}

Madin-Darby canine kidney (MDCK) and A549 cells were purchased from the American Type Culture Collection (ATCC), which were grown in monolayer culture with Dulbecco's modified eagle medium (DMEM/F12) supplemented with $10 \%$ fetal calf serum (FCS). Influenza virus A/Puerto Rico/8/34 (H1N1) was purchased from the ATCC, which was grown in MDCK cells in serumfree DMEM/F12 containing $2 \mu \mathrm{g} / \mathrm{mL} \mathrm{N}$-p-tosyl-Lphenylalanine chloromethyl ketone (TPCK)-treated trypsin. Subsequently, stocks of the virus were aliquoted and immediately frozen at $-80^{\circ} \mathrm{C}$ until use.

\section{Reagents and materials}

Isorhamnetin was prepared in our laboratory with high performance liquid chromotography (HPLC) purity $98 \%$. Electrospray ionization mass spectrometry (ESI-MS) $\mathrm{m} / \mathrm{z}$ : $317.0659\left[\mathrm{M}^{+} \mathrm{H}\right]^{+} .{ }^{1} \mathrm{H}-\mathrm{NMR}$ [400 MHz, dimethyl sulfoxide (DMSO)-d6] $\delta: 7.73\left({ }^{1} \mathrm{H}, \mathrm{d}, \mathrm{J}=2.2 \mathrm{~Hz}, \mathrm{H}-2\right.$ '), $7.64\left({ }^{1} \mathrm{H}, \mathrm{dd}\right.$, $\left.\mathrm{J}=8.3,2.1 \mathrm{~Hz}, \mathrm{H}-6^{\prime}\right), 6.94\left({ }^{1} \mathrm{H}, \mathrm{d}, \mathrm{J}=8.3 \mathrm{~Hz}, \mathrm{H}-5^{\prime}\right), 6.43\left({ }^{1} \mathrm{H}\right.$, d, J=2.1 Hz, H-8), $6.19\left({ }^{1} \mathrm{H}, \mathrm{d}, \mathrm{J}=2.1 \mathrm{~Hz}, \mathrm{H}-6\right), 3.74\left({ }^{3} \mathrm{H}, \mathrm{s}\right.$, $\left.3^{\prime}-\mathrm{OCH}_{3}\right) ;{ }^{13} \mathrm{C}-\mathrm{NMR}(100 \mathrm{MHz}, \mathrm{DMSO}-\mathrm{d} 6) \delta: 181.3$ (C-4), 165.7 (C-7), 163.8 (C-2), 160.5 (C-5), 157.2 (C-9), 148.9 (C-4'), 145.7 (C-3'), 121.5 (C-1'), 121.3 (C-6'), 114.8 (C-5'), 113.5 (C-2'), 103.5 (C-3), 103.0 (C-10), 99.1 (C-6), $93.5(\mathrm{C}-8), 56.5\left(-\mathrm{OCH}_{3}\right)$. The 3-(4,5-dimethylthiazol-2yl)-2,5-diphenyl tetrazolium bromide (MTT) and DMSO were purchased from the Sigma-Aldrich Chemicals Co.,
(St. Louis, MO, USA). Antibodies from Cell Signaling Technology ${ }^{\circledR}$ Inc. (Danvers, MA, USA) were listed in Table 1. Recombinant human IFN- $\beta$ were bought from PeproTech Inc. (Rocky Hill, NJ, USA). The enzymelinked immunosorbent assay (ELISA) kit was purchased from Multi-sciences (Lianke Biotech, Co., Ltd., Hangzhou, Zhejiang, China) [IL-6, EK106P; interferon inducible protein (IP)-10, EK168P; monocyte chemotactic protein (MCP)-1, EK187P].

\section{Cytotoxic assay}

Cytotoxic activities of isorhamnetin on A549 and MDCK cells were determined by MTT. We grew A549 and MDCK cells in a $96-$ well plate for $24 \mathrm{~h}$. The medium was replaced with fresh medium containing serially diluted isorhamnetin (A549 0, 1.25, 2.5 , 5, 9.9, 19.8, 39.5, 79, 158, $316 \mu \mathrm{M}$; MDCK 0, 2.5, 9.9, 19.8, 39.5, 79, 158, 316, $632 \mu \mathrm{M})$ and the cells were further incubated for $48 \mathrm{~h}$. The culture medium was discarded and replaced with fresh medium containing $0.5 \mathrm{mg} / \mathrm{mL}$ MTT (Sigma) solution at $37^{\circ} \mathrm{C}$ for another $4 \mathrm{~h}$. After removal of supernatant, $50 \mu \mathrm{L}$ of DMSO was added for solubilization of formazan crystals and incubated for $30 \mathrm{~min}$. The optical density (OD) was measured at $570 \mathrm{~nm}$ in a microplate reader. The $50 \%$ toxicity concentration $\left(\mathrm{TC}_{50}\right)$ of the drug was calculated by GraphPad Prism5 software (GraphPad Software, La Jolla, CA, USA). The $\mathrm{TC}_{50}$ was defined as the concentration of isorhamnetin required to reduce the absorbance of mockinfected cells by $50 \%$.

\section{Cytopathic effect}

While in the exponential growth phase $\left(3 \times 10^{4}\right.$ cells per well), MDCK cells were inoculated in a 96 -well plate. 
Table 2 Primers and probe sequences for qRT-PCR

\begin{tabular}{|c|c|c|}
\hline Gene & $\begin{array}{l}\text { Primers and } \\
\text { probe }\end{array}$ & Sequence $\left(5^{\prime} \rightarrow 3^{\prime}\right)$ \\
\hline \multirow[t]{3}{*}{ RIG-I } & Forward & GATGCTCTGGATTACTTG \\
\hline & Reverse & GTGGTACTCTTCTTGTAAG \\
\hline & Probe & CTTCTTCAGCAATGTCCGAGCAG \\
\hline \multirow[t]{3}{*}{ TNF- $\alpha$} & Forward & ААСАТССААССТTСССАAАCG \\
\hline & Reverse & GACССTAAGСССССААТTСТC \\
\hline & Probe & СССССТССТTСАGАСАСССТСААСС \\
\hline \multirow[t]{3}{*}{ IL-6 } & Forward & CGGGAACGAAAGAGAAGCTCTA \\
\hline & Reverse & CGCTTGTGGAGAAGGAGTTCA \\
\hline & Probe & TCCCCTCCAGGAGCCCAGCT \\
\hline \multirow[t]{3}{*}{ IP-10 } & Forward & GAAATTATTCCTGCAAGCCAATTT \\
\hline & Reverse & TCACCCTTCTTTTTCATTGTAGCA \\
\hline & Probe & TCCACGTGTTGAGATCA \\
\hline \multirow[t]{3}{*}{ IFN- $\alpha$} & Forward & $\begin{array}{l}\text { AGAATCACTCTCTATCTGAAAGAG- } \\
\text { AAGAAATA }\end{array}$ \\
\hline & Reverse & TCATGATTTCTGCTCTGACAACCT \\
\hline & Probe & AGCCCTTGTGCCTGG \\
\hline \multirow[t]{3}{*}{ MCP-1 } & Forward & CAAGCAGAAGTGGGTTCAGGAT \\
\hline & Reverse & AGTGAGTGTTCAAGTCTTCGGAGTT \\
\hline & Probe & CATGGACCACCTGGACAAGCAAACC \\
\hline \multirow[t]{3}{*}{ CCL-5 } & Forward & CAGCAGTCGTCTTTGTCACC \\
\hline & Reverse & GTTGATGTACTCCCGAACCC \\
\hline & Probe & CGCCAAGTGTGTGCCAACCC \\
\hline \multirow[t]{3}{*}{ GAPDH } & Forward & GAAGGTGAAGGTCGGAGTC \\
\hline & Reverse & GAAGATGGTGATGGGATTTC \\
\hline & Probe & CAAGCTTCCCGTTCTCAGCC \\
\hline
\end{tabular}

After infection, cells were cultured in media supplemented with $2 \mu \mathrm{g} / \mathrm{mL}$ trypsin tosyl phenylalanyl chloromethyl ketone (TPCK). After cells were cultured as monolayers, the culture medium was aspirated and the cells are infected with influenza virus $\left(100 \mathrm{TCID}_{50}\right)$ for $2 \mathrm{~h}$, then incubated with the cell maintenance medium with or without the addition of different dilutions of isorhamnetin. After further incubation for $48 \mathrm{~h}$, cytopathic changes were recorded and the $50 \%$ inhibitory concentration $\left(\mathrm{IC}_{50}\right)$ and selectivity index (SI) values were calculated following the method of Reed and Muench (25). The SI was defined as the ratio of
$\mathrm{TC}_{50}$ to $\mathrm{IC}_{50}$ to indicate the safety of treatment, while $\mathrm{IC}_{50}$ was defined as the concentration of isorhamnetin required to reduce viral infection by $50 \%$.

\section{Quantitative real-time polymerase chain reaction analysis}

The A549 cells were grown at about $90 \%$ confluence, infected with influenza $\mathrm{A} / \mathrm{PR} / 8 / 34(\mathrm{H} 1 \mathrm{~N} 1)$ virus $(\mathrm{MOI}=0.1)$, and cultured in the presence of isorhamnetin at various concentrations. After the cells in the above groups were lysed with TRIzol reagent (Thermo Fisher Scientific, Waltham, MA, USA) and RNA was extracted, RIG-I mRNA, TNF- $\alpha$ mRNA, IL-6 mRNA, IP-10 mRNA, IFN- $\alpha$ mRNA, monocyte chemotactic protein (MCP)-1 and C-C Motif Chemokine Ligand (CCL) 5 were measured by 2-step qRT-PCR using primers reported as Table 2 showed, and the relative quantitative $2^{-\Delta \Delta \mathrm{Ct}}$ was used to analyze the expression level of target genes in each sample.

\section{Western blotting}

Total protein was extracted from A549 cells using cold RIPA lysis buffer containing phosphatase inhibitor. Then, their protein concentrations were subsequently measured by using bicinchoninic acid (BCA) protein assay. After addition of sodium dodecyl sulfate (SDS) loading buffer, equivalent amounts of protein were heated $\left(100{ }^{\circ} \mathrm{C}\right.$; $10 \mathrm{~min}$ ) and separated by gel electrophoresis using SDSpolyacrylamide gel ecectrophoresis (PAGE), followed by transfer onto polyvinylidene fluoride (PVDF) membrane. After blocking, the membranes were incubated with specific primary antibodies $(1: 1,000)$ and then incubated with secondary antibodies $(1: 5,000)$. Finally, the specific proteins were visualized in a luminescent image analyzer and semiquantitative analysis was performed based on the gray value of the band.

\section{ELISA}

The supernatant of the cell culture was collected and cryopreserved at $-80{ }^{\circ} \mathrm{C}$ for quantification of cytokines using a specific ELISA kit according to the manufacturer's instructions.

\section{Molecular docking}

Docking calculations were carried out using Autodock software (Auto Dock Tools-1.5.6). The crystal structures 

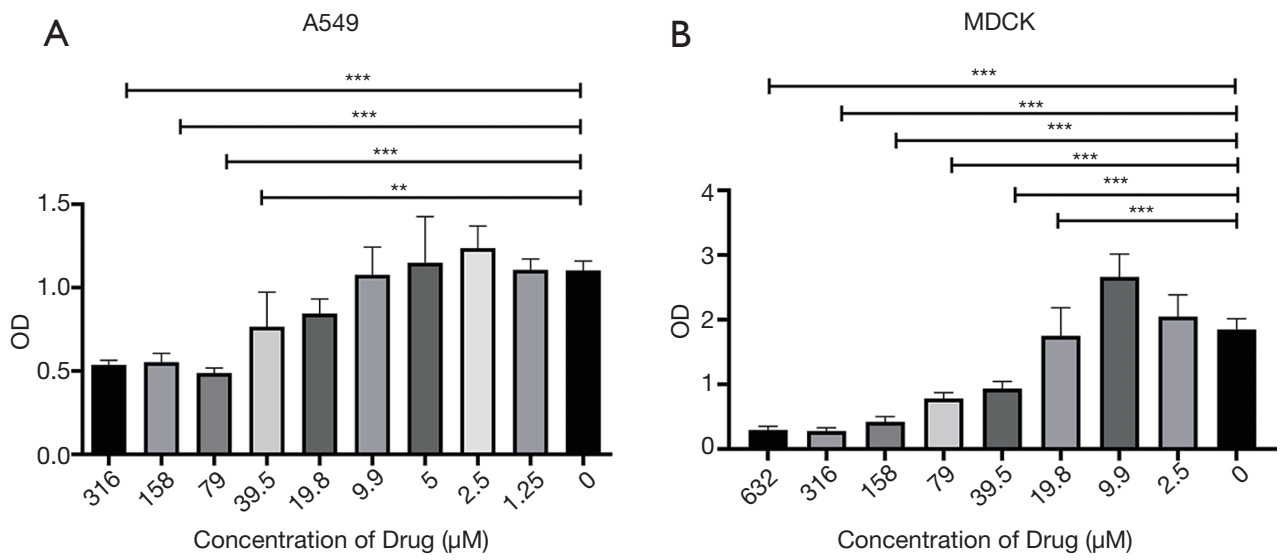

Figure 2 The cytotoxic effects of isorhamnetin on MDCK cells and A549 cells. Indicated concentrations of isorhamnetin were added to A549 (A) or MDCK cells (B) and incubated for $48 \mathrm{~h}$. Cell viability was determined by MTT assay. Data are presented as mean \pm SD ( $\mathrm{n}=3$ ) and are representative of at least 3 independent experiments. ${ }^{* *} \mathrm{P}<0.01$ and ${ }^{* * *} \mathrm{P}<0.001$. SD, standard deviation; MDCK, Madin-Darby canine kidney; MTT, 3-(4,5-dimethylthiazol-2-yl)-2,5-diphenyl tetrazolium bromide.

of the protein targets, JNK1 (PDBID: 4HYU), JNK2 (PDBID: 3NPC), and JNK3 (PDBID: 7KSI) were retrieved from Research Collaboratory for Structural Bioinformatics Public Database (RCSB-PDB, http://www.rcsb.org).

\section{Statistical analysis}

Statistical differences between two-group or multiple comparisons were evaluated by one-way analysis of variance (ANOVA), and then the Student-Newman-Keuls multiple comparison tests were performed to evaluate. $\mathrm{P}$ value of less than 0.05 was considered statistically significant.

\section{Results}

\section{Cytotoxicity of isorbamnetin on MDCK cells and A549} cells

In this study, we first evaluated the cytotoxicity of isorhamnetin on MDCK cells and A549 cells. In this assay, the OD value of the ordinate reflected the number of living cells. In A549 cells, isorhamnetin showed no toxicity below $39.5 \mu \mathrm{M}(\mathrm{P}<0.01$; Figure $2 A)$ and the $50 \%$ toxicity concentration $\left(\mathrm{TC}_{50}\right)$ was $129.9 \mu \mathrm{M}$. Additionally, in MDCK cells, isorhamnetin also showed no toxicity below $19.8 \mu \mathrm{M}(\mathrm{P}<0.001$; Figure $2 B)$ and $\mathrm{TC}_{50}$ was $60.5 \mu \mathrm{M}$.

\section{Isorbamnetin showed the apparent antiviral effect of H1N1 in vitro}

At $48 \mathrm{~h}$ post-infection, the cells in the IAV-infected group appeared obviously rounded, clumped, and fragmented under the microscope, unlike the cells in the mock-infected group, which grew adherently, with clear edges (Figure 3). Compared with IAV-infected cells, infected cells treated with $63.2 \mu M$ isorhamnetin had a significantly higher cell survival rate. The cytopathic effect (CPE) induced by IAV was decreased by isorhamnetin treatment in a dosedependent manner. As the concentration of the drug increased, CPE phenomena, such as cell fragmentation and shedding, gradually lessened. The calculated $\mathrm{IC}_{50}$ of isorhamnetin is $8.4 \mu \mathrm{M}$, and its SI is 7.2.

\section{Isorbamnetin inhibits the excessive inflammatory response induced by IAV (H1N1)}

To explore the anti-inflammatory effect of isorhamnetin at the doses of $15.8 \mu \mathrm{M}(5 \mu \mathrm{g} / \mathrm{mL})$ and $31.6 \mu \mathrm{M}(10 \mu \mathrm{g} / \mathrm{mL})$, we measured the levels of inflammatory cytokines in A549 cells at $24 \mathrm{~h}$ post-infection with influenza virus $\mathrm{A} / \mathrm{PR} / 8 / 34$ (H1N1) by performing qRT-PCR. We found that IAV infection significantly increased the levels of TNF- $\alpha$, IL-6, IP-10, and IFN- $\alpha$ in A549 cells, and the induction of these 

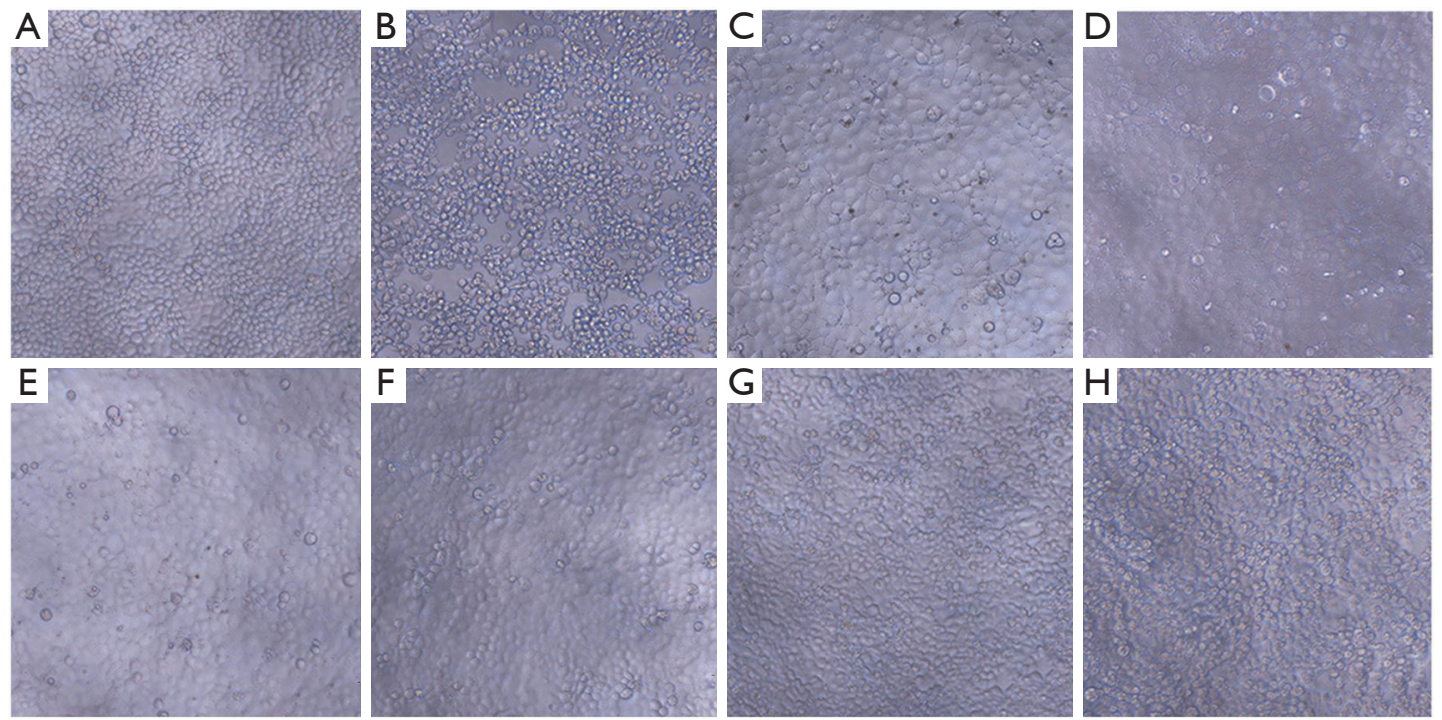

Figure 3 Microscopic observation of the effect of different doses of isorhamnetin on the CPE of normal MDCK cells and influenza virus H1N1 infected MDCK cells (×200). (A) Normal cell group; (B) Virus group; (C) $63.2 \mu M$ isorhamnetin; (D) Virus +63.2 $\mu \mathrm{M}$ isorhamnetin; (E) Virus +31.6 $\mu \mathrm{M}$ isorhamnetin; (F) Virus +15.8 $\mu \mathrm{M}$ isorhamnetin; (G) Virus +7.9 $\mu \mathrm{M}$ isorhamnetin; (H) Virus $+4.0 \mu \mathrm{M}$ isorhamnetin. CPE, cytopathic effect; MDCK, Madin-Darby canine kidney.

cytokines was attenuated by administration of isorhamnetin in a dose-dependent manner (Figure 4A). Cyclooxygenase 2 (COX-2), a key enzyme for the conversion of arachidonic acid to prostaglandins, which is highly expressed after IAV infection and participates in the pro-inflammatory cascade of IAV $(14,26)$, was also inhibted by isorhamnetin in a dosedependent manner (Figure 4B,4C).

\section{Isorhamnetin regulates the RIG-I-mediated $7 \mathrm{NK} / \mathrm{p} 38$ MAPK signaling pathway}

The molecular pathogenesis of the inflammatory response induced by IAV infection involves the activation of multiple signaling molecules. As our qRT-PCR results showed that isorhamnetin can inhibit the level of RIG-I mRNA (Figure 5A), we evaluated the effect of isorhamnetin on the RIG-I pathway in IAV (H1N1)-infected cells. We found that the levels of RIG-I protein were significantly increased after IAV (H1N1) infection. As expected, isorhamnetin treatment decreased the expression levels of RIG-I protein in IAV (H1N1)-infected cells (Figure 5B,5C). We speculated that the signaling molecules downstream of RIG-I, such as proteins in the JNK and p38 MAP kinase pathways, should be similarly restricted in the presence of isorhamnetin. As expected, the phosphorylation levels of JNK and p38 mitogen activated protein kinase (MAPK) were inhibited by isorhamnetin. These results suggest that isorhamnetin exerts an inhibitory effect on RIG-I and its downstream pathways, the JNK and p38 MAP kinase signaling pathways, during IAV infection.

\section{RIG-I-mediated production of IFN and the IFN-amplified pro-inflammatory response is inbibited by isorhamnetin}

In addition to affecting the pro-inflammatory cytokine levels, the inhibitory effect of isorhamnetin also altered the expression level of IFN- $\alpha$ in IAV-infected cells. The results of qRT-PCR experiment demonstrated a markedly lower level of IFN- $\alpha$ expression in isorhamnetin-treated cells (Figure 4A). We next hypothesized that the antiinflammatory effect mediated by isorhamnetin could be related to IFN. Although IFN is well known as an important host antiviral defense molecule (27), it has also been shown to have pro-inflammatory effects, which may be related to the formation of feedback amplification loops with IFN paracrine signaling to neighboring cells, leading to uncontrolled inflammation $(6,12)$. Therefore, we speculated that upregulation of IFN- $\alpha$ promoted the inflammatory response mediated by IAV. To test this, we pretreated A549 cells with IFN- $\beta$ ( $50 \mathrm{ng} / \mathrm{mL})$ for $4 \mathrm{~h}$ followed by 

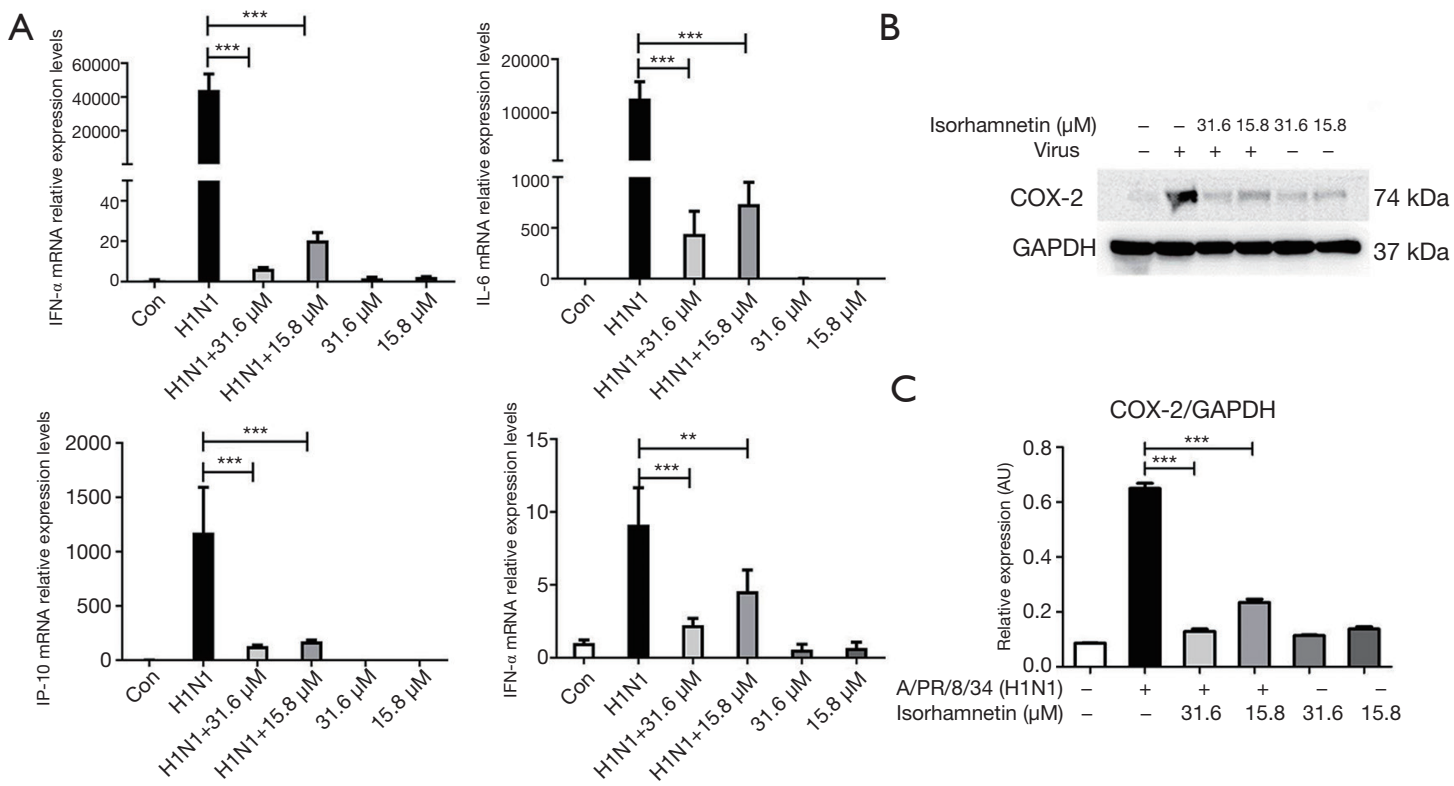

Figure 4 Isorhamnetin inhibits the expression of TNF- $\alpha$, IL-6, IP-10, and IFN- $\alpha$ mRNA levels and COX-2 protein levels induced by IAV (H1N1) infection in A549 cells. After allowing $2 \mathrm{~h}$ for H1N1 absorption, H1N1-infected A549 cells were treated with or without the indicated concentrations of isorhamnetin for $24 \mathrm{~h}$. (A) The gene expression levels of proinflammatory cytokines and chemokines in H1N1-infected A549 cells treated with or without isorhamnetin were determined using qRT-PCR at 24 h. (B) Immunoblot analysis was performed to evaluate the protein expression of COX-2. GAPDH was used as the internal control. (C) The band intensities of COX-2 were semiquantified using imageJ (normalized to the loading control GAPDH). The data are presented as the mean $\pm \mathrm{SEM}\left(\mathrm{n}=3\right.$ ). ${ }^{* *} \mathrm{P}<0.01$ and ${ }^{* * *} \mathrm{P}<0.001$. IAV, influenza A virus; qRT-PCR, quantitative real-time polymerase chain reaction; TNF- $\alpha$, tumor necrosis factor- $\alpha$; IP-10, interferon-inducible protein; IFN- $\alpha$, interferon- $\alpha$; GAPDH, glyceraldehyde 3-phosphate dehydrogenase; SEM, standard error of the mean.

IAV infection to simulate the inflammation amplification effect caused by the paracrine effect of IFN- $\beta$ (28). Interestingly, the messenger RNA (mRNA) and protein levels of several cytokines and chemokines (including IL-6, IP-10, MCP-1, CCL5, IFN- $\alpha$ and COX-2) were significantly elevated in IAV (H1N1)-infected cells that had been pretreated with IFN- $\beta$. As expected, isorhamnetin treatment was able to inhibit the increase in cytokine and chemokine (including IL-6, IP-10, MCP-1 and COX-2) levels induced by IFN- $\beta$ (Figure 6).

We then tested the anti-inflammatory mechanism of isorhamnetin. We observed that the protein levels of RIG-I and its downstream signaling molecule phosphorylated-JNK were significantly upregulated in IAV (H1N1)-infected cells that had been pretreated with IFN- $\beta$ and that isorhamnetin could dose-dependently inhibit this upregulation but did not appear to significantly inhibit the phosphorylation level of p38 (Figure 7). Previous studies have shown that COX-2 is also involved in the cytokine cascade triggered by IAV (14) and that RIG-I is the mediator for IAV (H1N1)-induced
COX-2 expression in A549 cells (29). As expected, our data showed that isorhamnetin inhibits the expression of COX-2, possibly owing to inhibition of the RIG-I signaling pathway. Most importantly, these results indicate that isorhamnetin treatment decreases the IFN- $\beta$-enhanced inflammatory response in IAV-infected cells.

\section{Molecular docking studies revealed that isorbamnetin can interact with the $\mathcal{F N K}$}

To gain structural and functional insight into the mechanism of interaction between isorhamnetin and JNK, we performed a virtual docking validation in which we examined the interactions between isorhamnetin and JNK using AutoDock software. This approach allowed us to examine the binding conformation and detailed interaction information for the active ingredients and their related protein targets. We also observed the ligand docking of the three-dimensional (3D) structures of JNK1/2/3 with both the structure of isorhamnetin and known ligands 
A

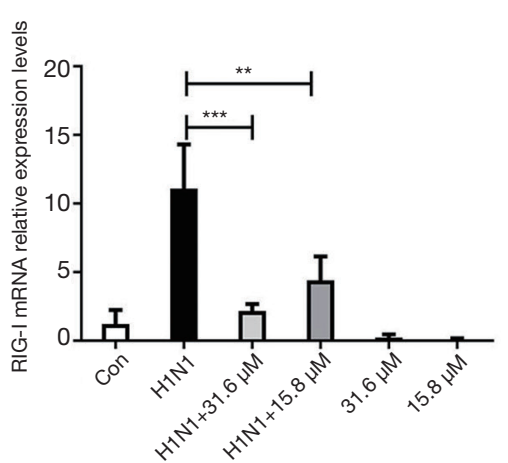

B

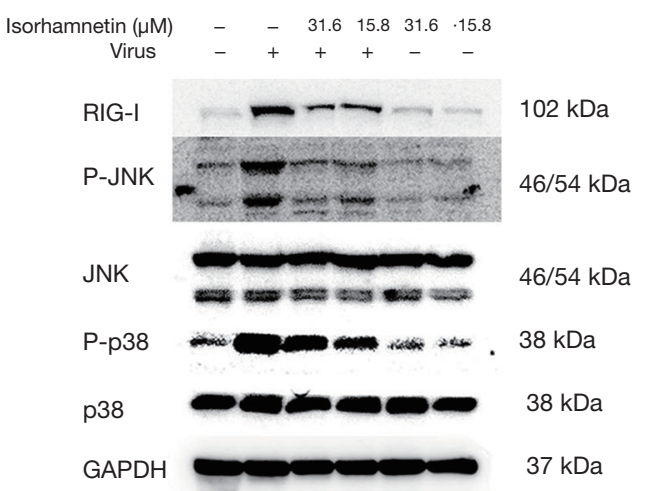

C

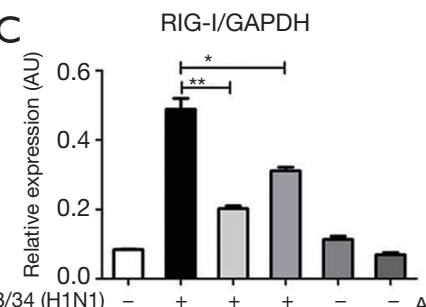

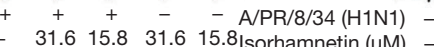

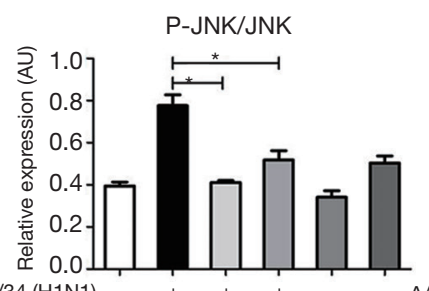

P-JNK/JNK

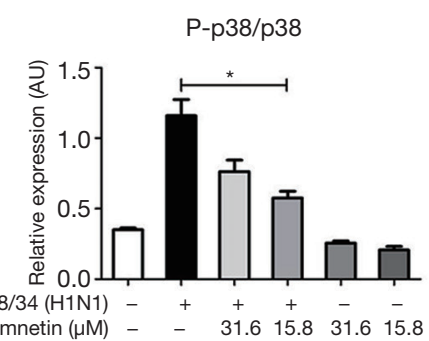

Figure 5 Isorhamnetin inhibits phosphorylation of JNK, p38 MAPK proteins and expression of RIG-I. After allowing $2 \mathrm{~h}$ for H1N1 absorption, H1N1-infected A549 cells were treated with or without the indicated concentrations of isorhamnetin for 24h. (A) The gene expression levels of RIG-I in H1N1-infected A549 cells treated with or without isorhamnetin were determined using qRT-PCR at 24h. (B) Expression of RIG-I/JNK and p38 MAPK signals in the H1N1-infected A549 cells. Cells were examined by western blotting for the expression of RIG-I, P-JNK, JNK, P-p38, p38 24 h post infection. (C) The band intensities of RIG-I, P-JNK and P-p38 were semiquantified using imageJ (normalized to the loading control GAPDH). The data are presented as the mean \pm SEM $(\mathrm{n}=3)$. ${ }^{*} \mathrm{P}<0.05,{ }^{* *} \mathrm{P}<0.01$ and ${ }^{* * *} \mathrm{P}<0.001$. qRT-PCR, quantitative real-time polymerase chain reaction; GAPDH, glyceraldehyde 3-phosphate dehydrogenase; SEM, standard error of the mean.

of JNK1/2/3 (1BK/B96/7KSI) as reference compounds. The molecular docking results showed that isorhamnetin and 1BK/B96/7KSI have similar binding energies and can interact with the JNK complex via hydrogen bonding interactions, but the molecular binding affinity of isorhamnetin is higher (Table 3). Some of the local structures revealed by the molecular docking results are illustrated in detail in Figure 8.

\section{Discussion}

In this study, we found evidence that IFN exerts a proinflammatory effect in influenza. More importantly, isorhamnetin inhibited the IFN-mediated amplification of inflammation induced by IAV (H1N1) via the RIG-I/JNK pathway in vitro. We also determined that isorhamnetin has anti-influenza virus activity and can significantly decrease the IAV (H1N1) infection-induced inflammatory response via blocking the RIG-I/JNK and p38 MAPK signaling pathways (Figure 9).

Influenza virus has a complex relationship with type I IFN $(12,13)$. This phenomenon may be due to the inflammatory cascade mediated by type I IFN. It has been reported that the concentration and timing of IFN exposure are critical parameters underlying the biological effect of type I IFN. Higher IFN- $\alpha / \beta$ signals increase inflammation and cell death without further enhancing the induction of antiviral effectors $(30,31)$. We speculated that IFN may have an inflammatory amplification effect during IAV (H1N1) infection. To test this, we pretreated A549 cells with IFN- $\beta$ $(50 \mathrm{ng} / \mathrm{mL})$ for $4 \mathrm{~h}$ and then infected them with IAV (H1N1). Confirming our hypothesis, the results showed that, compared with the mock-pretreatment virus infection group, the IFN- $\beta$ pretreatment virus infection group had an 

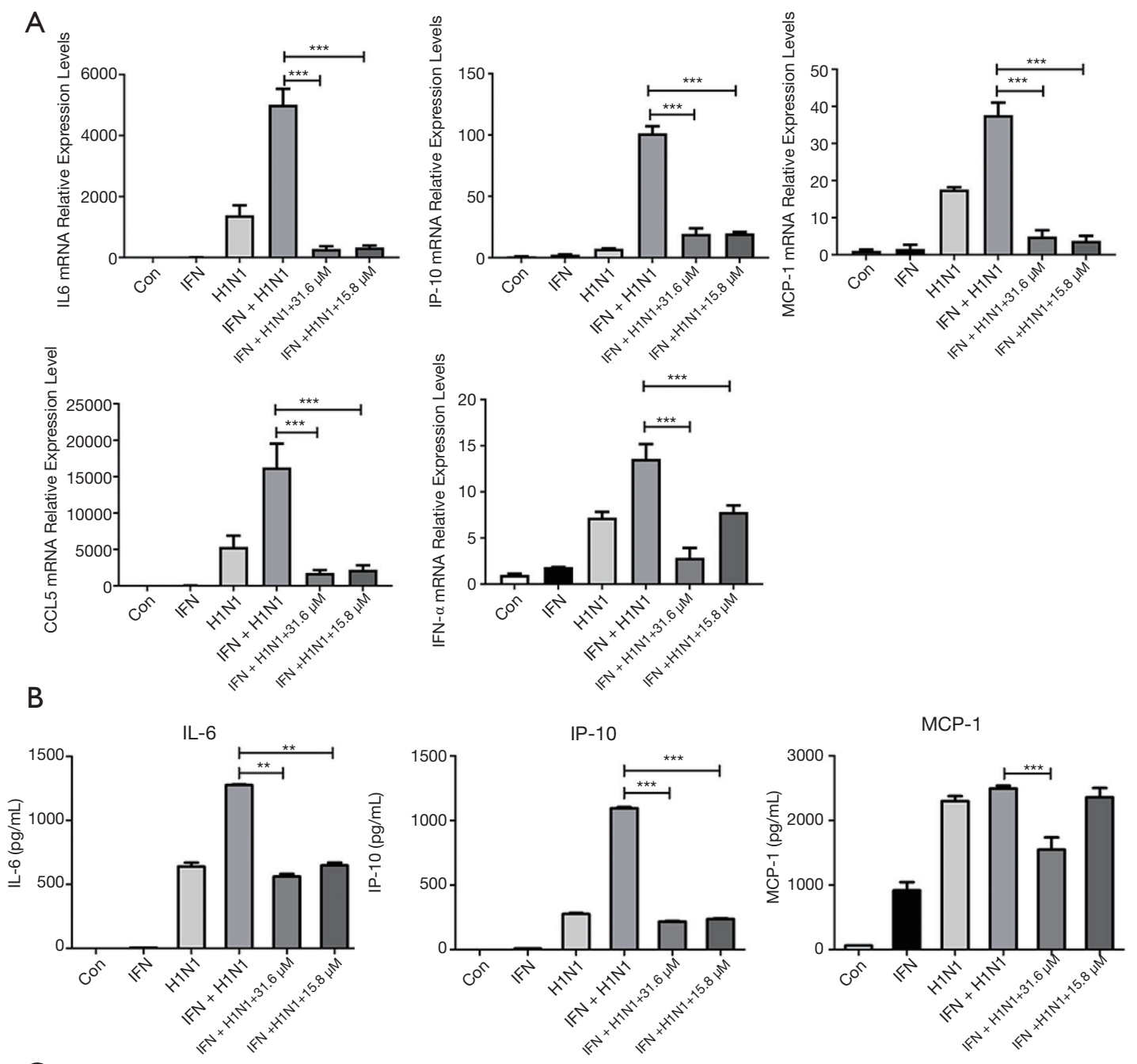

C
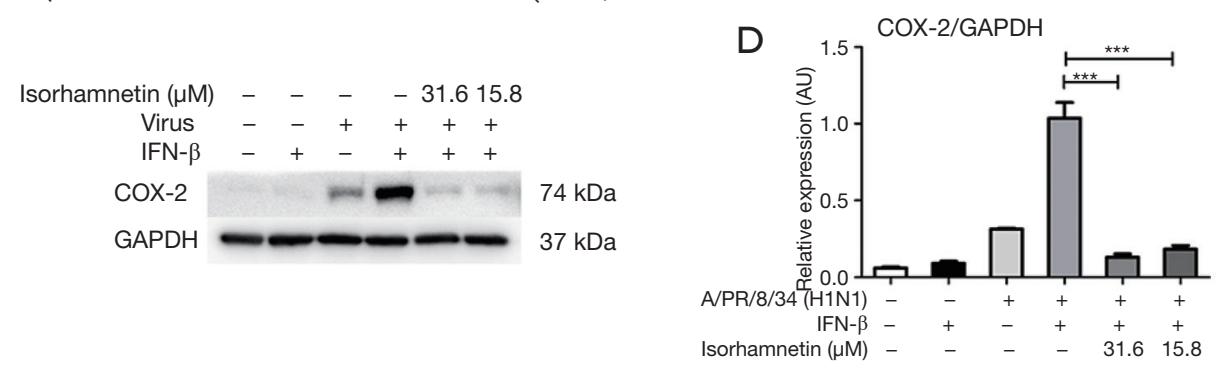

Figure 6 Isorhamnetin inhibited excessive secretion of pro-inflammatory cytokines in IAV (H1N1)-infected cells pretreated with IFN- $\beta$. (A) The effect of isorhamnetin on the IFN- $\beta$-mediated amplification of H1N1-induced proinflammatory cytokines and chemokines at the mRNA levels was determined by RT-PCR; (B) the effect of isorhamnetin on the IFN- $\beta$-mediated amplification of H1N1-induced proinflammatory cytokines and chemokines at the protein level was determined by ELISA assay; (C,D) immunoblot analysis was performed to evaluate the protein expression of COX-2. GAPDH was used as the internal control. The data are presented as the mean \pm SEM $(\mathrm{n}=3) .{ }^{* *} \mathrm{P}<0.01$ and ${ }^{* *} \mathrm{P}<0.001$. IAV, influenza A virus; mRNA, messenger RNA; RT-PCR, real-time polymerase chain reaction; IFN- $\beta$, interferon- $\beta$; ELISA, enzyme-linked immunosorbent assay; GAPDH, glyceraldehyde 3-phosphate dehydrogenase; SEM, standard error of the mean. 


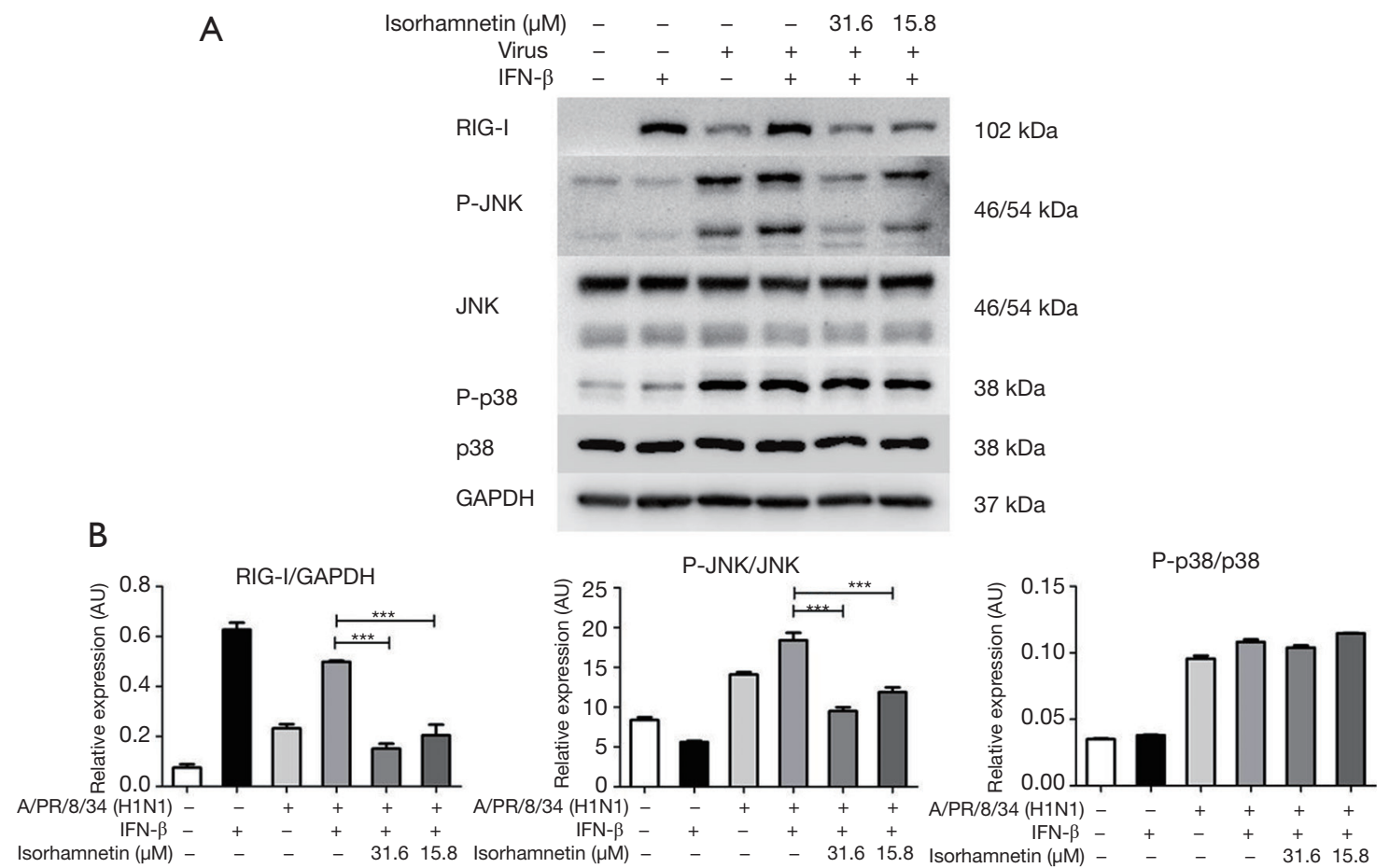

Figure 7 Isorhamnetin inhibited the inflammatory response of IFN- $\beta$-pretreated IAV infected cells via the RIG-I/JNK pathway. (A) Expression of RIG-I/JNK and p38 MAPK signals in IAV (H1N1)-infected A549 cells pretreated with IFN- $\beta$. Cells were examined by western blotting for the expression of RIG-I, phosphorylated-JNK, JNK, phosphorylated-p38, and p38 24 h post infection; (B) the band intensities of RIG-I, phosphorylated-JNK and phosphorylated-p38 were semiquantified using image (normalized to the loading control GAPDH). The data are presented as the mean $\pm \operatorname{SEM}(n=3)$. ${ }^{* *} \mathrm{P}<0.001$. IFN- $\beta$, interferon- $\beta$; IAV, influenza A virus; GAPDH, glyceraldehyde 3-phosphate dehydrogenase; SEM, standard error of the mean.

Table 3 Ligand-target binding affinity

\begin{tabular}{lccc}
\hline Ligand-target & Binding affinity $(\mathrm{kcal} / \mathrm{mol})$ & Ligand-target & Binding affinity $(\mathrm{kcal} / \mathrm{mol})$ \\
\hline Isorhamnetin-JNK1 & -7.61 & 4HYU-JNK1 & -9.01 \\
Isorhamnetin-JNK2 & -7.59 & 3NPC-JNK2 & -14.60 \\
Isorhamnetin-JNK3 & -8.69 & 7KSI-JNK3 & -11.03 \\
\hline
\end{tabular}

upregulated level of pro-inflammatory cytokine expression. Our findings suggest that the pro-inflammatory factors IL6, IP-10, MCP-1, CCL5, and IFN- $\alpha$ are overexpressed in IAV (H1N1)-infected cells pretreated with IFN- $\beta$. Like type I IFN, pro-inflammatory cytokines also act as a double-edged sword, in that they can promote the recruitment of immune cells to the site of infection to clear the virus but the excessive secretion of pro-inflammatory cytokines can cause severe lung tissue damage. Inhibiting the expression of these cytokines significantly increases the survival rate of IAV-infected mice, inhibits apoptosis, and decreases inflammatory injury $(32,33)$. Our results indicated that isorhamnetin can attenuate the overexpression of the pro-inflammatory factors IL-6, IP-10, and MCP-1 in IAV (H1N1)-infected cells that have been pretreated with IFN- $\beta$. Compared with the commonly used traditional Chinese medical formula Lianhua Qingwen, isorhamnetin has the advantages of a low anti-inflammatory dose (5-10 $\mathrm{gg} / \mathrm{mL}$ compared with $1.5-3 \mathrm{mg} / \mathrm{mL}$ for Lianhua Qingwen) and a higher selectivity index (7.2 compared with 
A

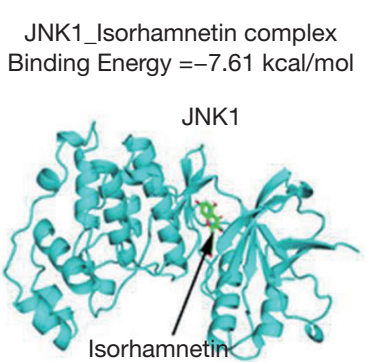

B

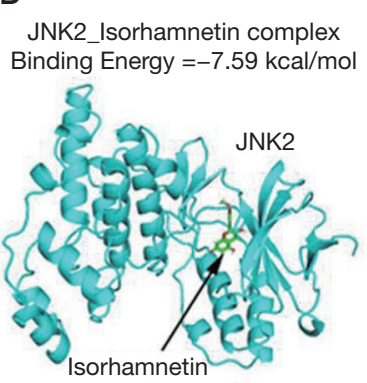

C

JNK3_Isorhamnetin complex Binding Energy $=-8.69 \mathrm{kcal} / \mathrm{mol}$

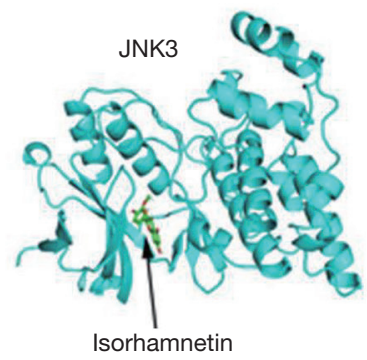

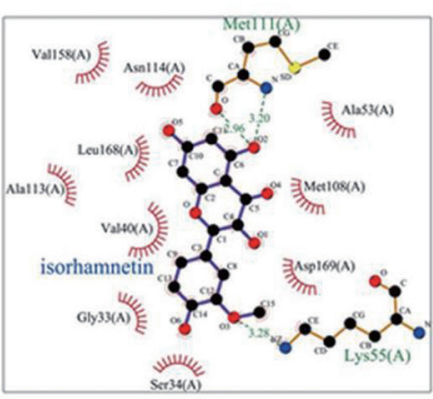
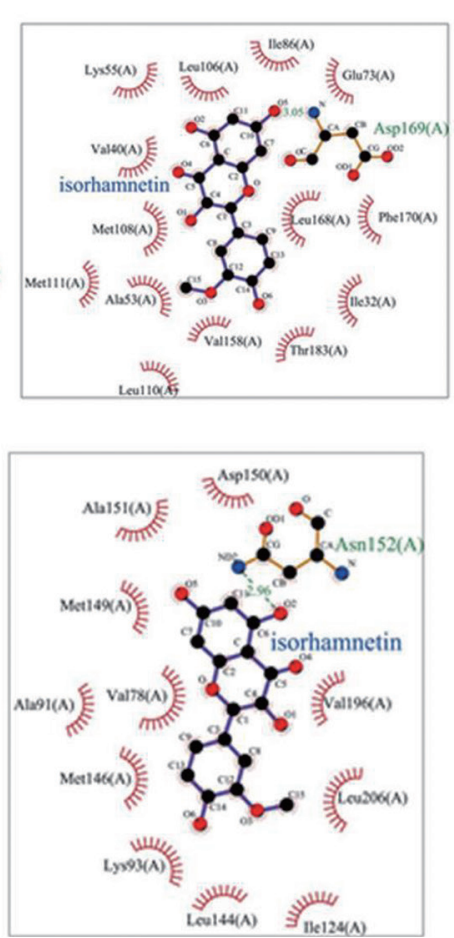

D

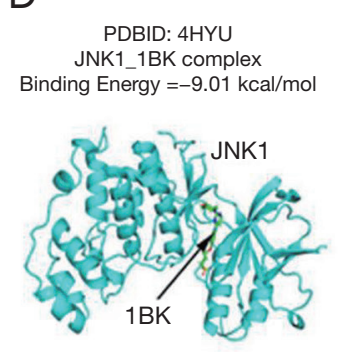

E

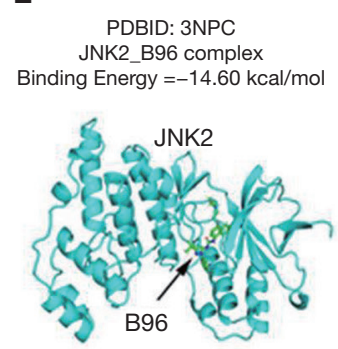

$\mathrm{F}$
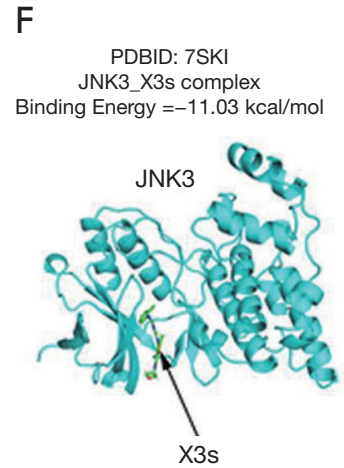

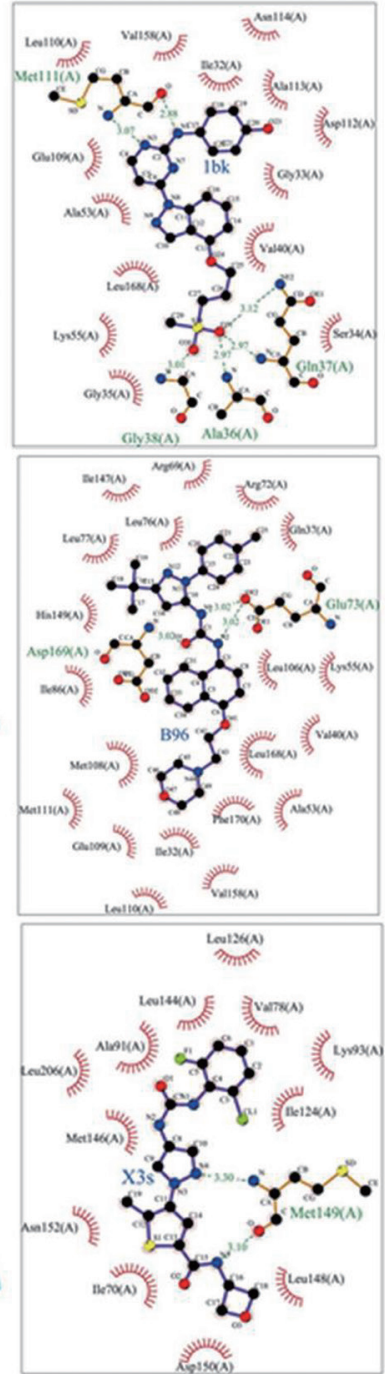

Figure 8 Computer molecular docking analysis of ligand isorhamnetin and JNK. (A-C) The 3D structure of JNK bound efficiently with compound isorhamnetin with its interacting amino acids Met111, Lys55, Asp169, and Asn152; (D-F) the 3D structure of JNK bound efficiently with the known ligand compounds with its interacting amino acids Met111, Gln37, Ala36, Gly38, Glu73, Asp169, and Met149.

\subsection{1 for Lianhua Qingwen) (34).}

During IAV infection, RIG-I plays a crucial role in the process of inducing type I IFN (35-37). Here, we confirmed the IFN-mediated inflammation amplification effect of RIG-I in IAV (H1N1) infection; the level of RIG-I protein was significantly upregulated under the co-stimulation of IFN- $\beta$ and IAV (H1N1). The upregulation of RIG-I in these cells was accompanied by an overexpression of proinflammatory cytokines, including IL-6, IP-10, MCP-1, CCL5, and IFN- $\alpha$. From previous research, we speculate that after being co-activated by influenza virus and IFN, overexpressed RIG-I activates downstream signaling pathways to generate IFN, forming a paracrine-signaling feedback amplification loop of IFN, which is accompanied by an excessive release of inflammatory cytokines (also known as a cytokine storm) (6). Our data indicate that RIG$\mathrm{I}$ is inhibited by isorhamnetin in a dose-dependent manner (5 and $10 \mu \mathrm{g} / \mathrm{mL}$ ), which suggests a possible mechanism by which isorhamnetin inhibits the overexpression of inflammatory factors. Alternately, because COX-2 drives and maintains the pro-inflammatory cascade via a positive feedback loop during IAV infection $(14,29)$, it is possible that isorhamnetin may also reduce the expression of COX2 by inhibiting RIG-I, thereby reducing the inflammatory 


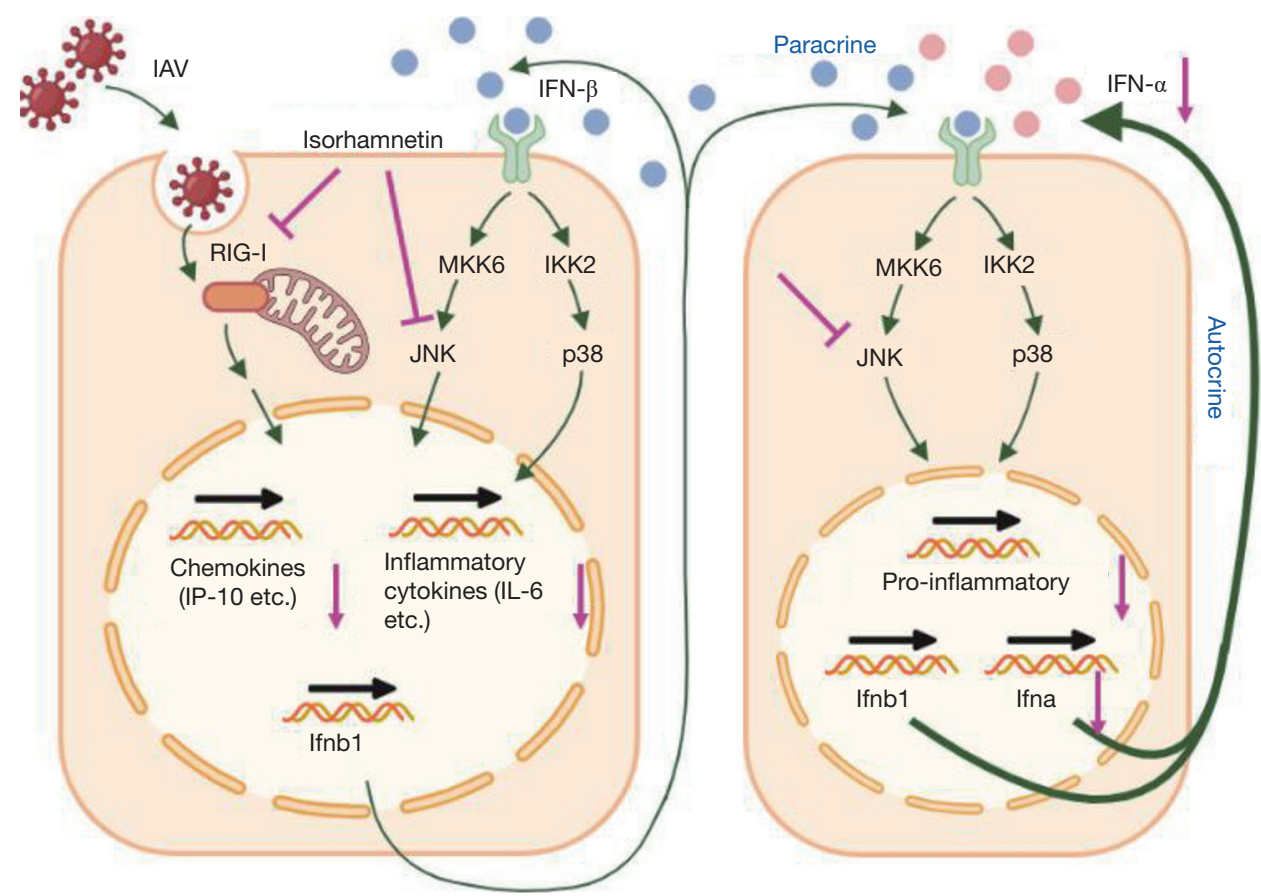

Figure 9 Diagrammatic sketch showing the mechanism by which isorhamnetin attenuates IAV (H1N1)-induced proinflammatory responses and injury. After infection, influenza virus is recognized by RIG-I, which induces the production of type I IFN, cytokines, and chemokines. The IFN- $\alpha$ and IFN- $\beta$ act on the IFN receptors (IFNARs) of adjacent cells via autocrine and paracrine activity to activate the MAPK pathway. This pathway is a cascade of protein kinases that is triggered by specific extracellular signals such as type I IFN. Upon extracellular stimulation, MAPKs are activated downstream of sequentially activated protein kinases, MAPK kinase kinase (MKKK) and MAPK kinase (MKK). Subsequently, JNK and p38, 2 MAPK family proteins, become continuously activated (i.e., phosphorylated) by multiple upstream kinases in the MAPK pathway, thus inducing the expression of pro-inflammatory and IFN. Following, IFN interacts with IFNAR in the form of paracrine or autocrine to cause positive feedback, accompanied by excessive release of pro-inflammatory cytokines. The inhibition of RIG-I signaling by isorhamnetin attenuates RIG-I-linked proinflammatory IFN production, which results in a reduction in JNK activation and thus a decrease in the amplification of proinflammatory responses. IAV, influenza A virus; IFN, interferon.

cascade via this route.

Influenza virus infection and cytokine stimulation can lead to the activation of JNKs, which are members of the MAPK family $(38,39)$. Upon IAV infection, JNK mediates the early activation of activator protein 1-transcription factors (AP-1), which in turn contributes to the upregulation of IFN- $\beta$ expression (38). Notably, the constitutive production of IFN- $\beta$ that initiates the autocrine or paracrine feedback loops required to maintain STAT1 expression is disrupted by JNK deficiency (40). Thus, JNK is essential for the production of type I IFN. As another member of the MAPK family, p38 is also involved in the production of IFN and pro-inflammatory factors during IAV infection. In vivo inhibition of p38 MAPK directly limited excessive cytokine expression through an IFN-dependent mechanism. This regulation is mediated via the phosphorylation of STAT1 and its subsequent engagement of the IFN- $\beta$ promotor to regulate interferon-stimulated gene (ISG) expression (41). Our results showed that the protein levels of P-JNK in IAV (H1N1)-infected cells that were pretreated with IFN- $\beta$ were significantly upregulated and that isorhamnetin could dose-dependently inhibit this upregulation whereas it did not significantly inhibit the phosphorylation level of p38. However, p38 could be inhibited by isorhamnetin in IAV (H1N1)-infected cells that were not pretreated with IFN. We speculate that the inhibitory effect of isorhamnetin on p38 may be inferior to its effect on JNK when the level of inflammation is amplified by IFN- $\beta$. In other words, isorhamnetin may predominantly reduce the IFN-amplified IAV (H1N1)-mediated inflammatory response by inhibiting the RIG-I/JNK pathway. The molecular docking results also indicated that isorhamnetin and JNK ligands have 
similar binding energies to JNK; these data further verified that isorhamnetin interacts with JNK. On the basis of this observation, we speculate that isorhamnetin mediates a reduction in the level of JNK activation, leading to a reduction in the expression of pro-inflammatory mediators in IAV (H1N1)-infected cells that were pretreated by IFN- $\beta$, by inhibiting RIG-I.

\section{Conclusions}

In summary, our study revealed that isorhamnetin significantly improves the excessive inflammatory response mediated by IAV (H1N1) infection mainly through affecting the RIG-I/JNK pathway rather than via its effects on $\mathrm{p} 38$. This work is the first to demonstrate the antiinflammatory mechanism of isorhamnetin during influenza virus infection. However, there were some shortcomings in our research. First, although we showed that treatment with isorhamnetin decreases type I IFN production to inhibit the IAV-triggered excessive inflammatory response, we did not evaluate whether the inhibition of type I IFN by isorhamnetin adversely affects the antiviral effect. Second, we did not further investigate why isorhamnetin does not exhibit an inhibitory effect on $\mathrm{p} 38$ in the presence of IFN- $\beta$. Thirdly, our research lacks verification by in vivo experiments. However, our research did demonstrate that isorhamnetin has a low effective dose and a high therapeutic index against the anti-inflammatory response triggered by influenza virus infection. Therefore, further research is needed to clarify how virus-mediated excessive inflammation is controlled by the innate immune response. Our research on the molecular mechanism by which isorhamnetin regulates RIG-I-mediated inflammation amplification during influenza virus infection may provide new ideas for the development of novel drugs for the treatment of influenza, especially in the field of severe influenza.

\section{Acknowledgments}

Funding: This work was supported by the Basic research program of Guangzhou (202102010224), Clinical Transformation program of the First Affiliated Hospital of Guangzhou Medical University (ZH201802, ZH201914), High-level University Program of Guangzhou Medical University (2017(160), Opening Project of State Key Laboratory of Respiratory Disease (SKLRD-0P-202115), and National Natural Science Foundation of China
(82004155); Guangzhou Science and Technology Plan Project (202102010215); Independent Project of State Key Laboratory of Respiratory Disease, Guangdong-Hong Kong-Macao Joint Laboratory of Respiratory Infectious Disease (202107).

\section{Footnote}

Reporting Checklist: The authors have completed the MDAR reporting checklist. Available at https://dx.doi. org/10.21037/atm-21-3532

Data Sharing Statement: Available at https://dx.doi. org/10.21037/atm-21-3532

Conflicts of Interest: All authors have completed the ICMJE uniform disclosure form (available at https://dx.doi. org/10.21037/atm-21-3532). The authors have no conflicts of interest to declare.

Ethical Statement: The authors are accountable for all aspects of the work in ensuring that questions related to the accuracy or integrity of any part of the work are appropriately investigated and resolved.

Open Access Statement: This is an Open Access article distributed in accordance with the Creative Commons Attribution-NonCommercial-NoDerivs 4.0 International License (CC BY-NC-ND 4.0), which permits the noncommercial replication and distribution of the article with the strict proviso that no changes or edits are made and the original work is properly cited (including links to both the formal publication through the relevant DOI and the license). See: https://creativecommons.org/licenses/by-nc-nd/4.0/.

\section{References}

1. Panayiotou C, Richter J, Bashiardes S, et al. Molecular epidemiology of influenza A virus infection in Cyprus in four consecutive seasons (2009 pandemic-2013). Epidemiol Infect 2014;142:975-83.

2. Neumann G, Noda T, Kawaoka Y. Emergence and pandemic potential of swine-origin $\mathrm{H} 1 \mathrm{~N} 1$ influenza virus. Nature 2009;459:931-9.

3. Allen JD, Ross TM. H3N2 influenza viruses in humans: Viral mechanisms, evolution, and evaluation. Hum Vaccin Immunother 2018;14:1840-7.

4. Liu Q, Zhou YH, Yang ZQ. The cytokine storm of severe 
influenza and development of immunomodulatory therapy. Cell Mol Immunol 2016;13:3-10.

5. Peiris JS, Hui KP, Yen HL. Host response to influenza virus: protection versus immunopathology. Curr Opin Immunol 2010;22:475-81.

6. Hui KP, Lee SM, Cheung CY, et al. H5N1 influenza virusinduced mediators upregulate RIG-I in uninfected cells by paracrine effects contributing to amplified cytokine cascades. J Infect Dis 2011;204:1866-78.

7. Iwasaki A, Pillai PS. Innate immunity to influenza virus infection. Nat Rev Immunol 2014;14:315-28.

8. Ivashkiv LB, Donlin LT. Regulation of type I interferon responses. Nat Rev Immunol 2014;14:36-49.

9. Murray PJ. The JAK-STAT signaling pathway: input and output integration. J Immunol 2007;178:2623-9.

10. Schneider WM, Chevillotte MD, Rice CM. Interferonstimulated genes: a complex web of host defenses. Annu Rev Immunol 2014;32:513-45.

11. Trinchieri G. Type I interferon: friend or foe? J Exp Med 2010;207:2053-63.

12. Davidson S, Crotta S, McCabe TM, et al. Pathogenic potential of interferon $\alpha \beta$ in acute influenza infection. Nat Commun 2014;5:3864.

13. Kugel D, Kochs G, Obojes K, et al. Intranasal administration of alpha interferon reduces seasonal influenza A virus morbidity in ferrets. J Virol 2009;83:3843-51.

14. Lee SM, Cheung CY, Nicholls JM, et al. Hyperinduction of cyclooxygenase-2-mediated proinflammatory cascade: a mechanism for the pathogenesis of avian influenza $\mathrm{H} 5 \mathrm{~N} 1$ infection. J Infect Dis 2008;198:525-35.

15. McKimm-Breschkin JL. Influenza neuraminidase inhibitors: antiviral action and mechanisms of resistance. Influenza Other Respir Viruses 2013;7 Suppl 1:25-36.

16. Pinto LH, Lamb RA. Influenza virus proton channels. Photochem Photobiol Sci 2006;5:629-32.

17. Moss RB, Davey RT, Steigbigel RT, et al. Targeting pandemic influenza: a primer on influenza antivirals and drug resistance. J Antimicrob Chemother 2010;65:1086-93.

18. Choi A, García-Sastre A, Schotsaert M. Host immune response-inspired development of the influenza vaccine. Ann Allergy Asthma Immunol 2020;125:28-35.

19. Sencanski M, Radosevic D, Perovic V, et al. Natural Products as Promising Therapeutics for Treatment of Influenza Disease. Curr Pharm Des 2015;21:5573-88.

20. Gong G, Guan YY, Zhang ZL, et al. Isorhamnetin: A review of pharmacological effects. Biomed Pharmacother 2020;128:110301.
21. Li J, Wu R, Qin X, et al. Isorhamnetin inhibits IL-1 $\beta$-induced expression of inflammatory mediators in human chondrocytes. Mol Med Rep 2017;16:4253-8.

22. Qi F, Sun JH, Yan JQ, et al. Anti-inflammatory effects of isorhamnetin on LPS-stimulated human gingival fibroblasts by activating Nrf2 signaling pathway. Microb Pathog 2018;120:37-41.

23. Dai W, Bi J, Li F, et al. Antiviral Efficacy of Flavonoids against Enterovirus 71 Infection in Vitro and in Newborn Mice. Viruses 2019;11:625.

24. Abdal Dayem A, Choi HY, Kim YB, et al. Antiviral effect of methylated flavonol isorhamnetin against influenza. PLoS One 2015;10:e0121610.

25. Dai JP, Zhao XF, Zeng J, et al. Drug screening for autophagy inhibitors based on the dissociation of Beclin1Bcl2 complex using BiFC technique and mechanism of eugenol on anti-influenza A virus activity. PLoS One 2013;8:e61026.

26. Liu L, Li R, Pan Y, et al. High-throughput screen of protein expression levels induced by cyclooxygenase-2 during influenza a virus infection. Clin Chim Acta 2011;412:1081-5.

27. Goraya MU, Wang S, Munir M, et al. Induction of innate immunity and its perturbation by influenza viruses. Protein Cell 2015;6:712-21.

28. Zhou B, Liang X, Feng Q, et al. Ergosterol peroxide suppresses influenza A virus-induced pro-inflammatory response and apoptosis by blocking RIG-I signaling. Eur J Pharmacol 2019;860:172543.

29. Dudek SE, Nitzsche K, Ludwig S, et al. Influenza A viruses suppress cyclooxygenase-2 expression by affecting its mRNA stability. Sci Rep 2016;6:27275.

30. Davidson S, Maini MK, Wack A. Disease-promoting effects of type I interferons in viral, bacterial, and coinfections. J Interferon Cytokine Res 2015;35:252-64.

31. Major J, Crotta S, Llorian M, et al. Type I and III interferons disrupt lung epithelial repair during recovery from viral infection. Science 2020;369:712-7.

32. Chen S, Liu G, Chen J, et al. Ponatinib Protects Mice From Lethal Influenza Infection by Suppressing Cytokine Storm. Front Immunol 2019;10:1393.

33. Wang W, Yang $\mathrm{P}$, Zhong $\mathrm{Y}$, et al. Monoclonal antibody against CXCL-10/IP-10 ameliorates influenza A (H1N1) virus induced acute lung injury. Cell Res 2013;23:577-80.

34. Ding Y, Zeng L, Li R, et al. The Chinese prescription lianhuaqingwen capsule exerts anti-influenza activity through the inhibition of viral propagation and impacts immune function. BMC Complement Altern Med 
2017;17:130.

35. Biondo C, Lentini G, Beninati C, et al. The dual role of innate immunity during influenza. Biomed J 2019;42:8-18.

36. Pang IK, Pillai PS, Iwasaki A. Efficient influenza A virus replication in the respiratory tract requires signals from TLR7 and RIG-I. Proc Natl Acad Sci U S A 2013;110:13910-5.

37. Weber-Gerlach M, Weber F. Standing on three legs: antiviral activities of RIG-I against influenza viruses. Curr Opin Immunol 2016;42:71-5.

38. Ludwig S, Ehrhardt C, Neumeier ER, et al. Influenza virus-induced $\mathrm{AP}-1$-dependent gene expression requires activation of the JNK signaling pathway. J Biol Chem

Cite this article as: Li J, Xu Y, Lin Z, Guan L, Chen S, Zhou L. Isorhamnetin inhibits amplification of influenza A $\mathrm{H} 1 \mathrm{~N} 1$ virus inflammation mediated by interferon via the RIG-I/JNK pathway. Ann Transl Med 2021;9(16):1327. doi: 10.21037/atm-21-3532
2001;276:10990-8.

39. Nacken W, Ehrhardt C, Ludwig S. Small molecule inhibitors of the c-Jun N-terminal kinase (JNK) possess antiviral activity against highly pathogenic avian and human pandemic influenza A viruses. Biol Chem 2012;393:525-34.

40. Gough DJ, Messina NL, Hii L, et al. Functional crosstalk between type I and II interferon through the regulated expression of STAT1. PLoS Biol 2010;8:e1000361.

41. Katsoulidis E, Li Y, Mears H, et al. The p38 mitogenactivated protein kinase pathway in interferon signal transduction. J Interferon Cytokine Res 2005;25:749-56. 